\title{
Endocrinology of the Carbohydrate-Deficient Glycoprotein Syndrome Type 1 from Birth through Adolescence
}

\author{
FRANCIS DE ZEGHER AND JAAK JAEKEN \\ Department of Pediatrics, University of Leuven, Belgium
}

\begin{abstract}
The carbohydrate-deficient glycoprotein (CDG) syndrome type 1 is a genetic multisystem disorder, characterized by hypoglycosylation of glycoproteins and presenting with neurologic impairment. In 12 girls and 14 boys, we confirmed the diagnosis of CDG syndrome type 1 by immune-isoclectric focusing of serum sialotransferrins, and we cxamined the endocrine status singly or sequentially, including a $16-y$ follow-up of the index cases, a pair of monozygotic girls. Scrum FSH levels were normal in newborns and prepubertal children, but elevated in fcmale toddlers and tecnagers, as well as in adolescent males. Serum LH concentrations displayed an analogous age-dependent pattern. In adolescent girls, scrum estradiol remained low. FSH bioactivity was low normal, as was the bioactive/immunoreactive FSH ratio. However, exogenous gonadotropins evoked an estradiol response and induced ovarian follicular growth. Male patients virilized at puberty; however, testicular volume was subnormal. The thyroid axis was hallmarked by thyroid-binding globin deficiency and, during infancy, increased serum TSH concentrations. A subgroup of female patients presented hypersomatotropism and/or hyperprolactinemia. During adolescence, the index cases responded to glucagon with normal glycemic, but
\end{abstract}

ABSTRACT
The CDG syndrome type 1 is a newly recognized inborn error of glycoprotein metabolism $(1,2)$. The biochemical hallmark of the disease is a partial carbohydrate deficiency of a wide range of glycoproteins, including binding proteins, enzymes, and coagulation factors (1-4). The primary defect is at present unknown, but available evidence indicates that the dysfunction is located at the level of the endoplasmic reticulum (4). The clinical picture is dominated by the affection of the central and peripheral nervous system, resulting in psychomotor retardation, seizures, ataxia, and strokelike episodes. However, other organ systems are also involved, resulting in e.g. an abnormal pattern of subcutaneous fat distribution, feeding difficulties, retinitis pigmentosa, hypoalbuminemia, pericardial

Received June 9, 1994; accepted November 3, 1994.

Correspondence and reprint requests: Francis de Zegher, Department of Pediatrics, University Hospital Gasthuisberg, 3000) Leuven, Belgium.

Supported in part by a grant from the Belgian Fund for Scientific Research (NFWO) and from Pharmacia. exaggerated insulin and paradoxally augmented growth hormone responses. The hypothalamo-pituitary area appeared intact on magnetic resonance imaging. Circulating IGF-1 levcls were in the lower normal range and transcortin concentrations decreased. In conclusion, a study of cndocrine aspects of a major glycosylation disorder revealed an age-dependent constellation, including hypergonadotropic hypogonadism with deficient FSH rather than LH action; transient hyperthyrotropinemia; inconsistent hyperprolactinemia; hyperglycemia-induced growth hormone release; deficiencics of hormone-binding glycoprotcins and possibly decreased insulin sensitivity, thus pointing to the importance of glycoprotein glycosylation for pediatric endocrinology. (Pediatr Res 37: 395-401, 1995)
CDG, carbohydrate-deficient glycoprotein
TBG, thyroxine-binding globulin
GnRH, gonadotropin-releasing hormone
TRH, TSH-relcasing hormone
GH, growth hormone

effusion, and/or ascites $(1,2,5)$. At present, the diagnosis of CDG syndrome type 1 has becn confirmed by isoelectric focusing of serum sialotransferrins in more than 100 children worldwide $(1,2)$. The CDG syndrome type 1 is clinically and biochemically distinct from the type 2 , which is known to be duc to a deficient activity of the Golgi enzyme $N$-acetylglucosaminyltransferase II (6).

Although endocrine abnormalities were originally described as one of the most striking features of the disorder (7), they have subsequently received little attention. Here, we report endocrine data from 26 affected children, including longitudinal observations from the index cases, now followed for $16 \mathrm{y}$.

\section{METHODS}

A total of 26 patients, 12 femalc and 14 male, ranging in age from $1 \mathrm{~d}$ to $20 \mathrm{y}$, were studied either singly $(n=19)$ or sequentially $(n=7)$. Nine patients are from Belgium, six from Italy, four from the United States, three from Germany, two 
from France, and one each from the United Kingdom and Austria. The examined group includes five pairs of siblings.

Three patients were examined as newborns (age $<1 \mathrm{mo}$ ), five as infants (age 1 mo to $1 \mathrm{y}$ ), 14 as toddlers (age $1-5 \mathrm{y}$ ), cight as children (age 6-9 y), and eight as adolescents or young adults (age 12-20 y).

In all patients, the diagnosis of CDG syndrome type 1 was confirmed in our laboratory by isoelectric focusing of serum sialotransferrins, showing a cathodal shift with significantly decreased tetrasialofraction and increased di- and a-sialofractions (1).

Standard RIA or immunoradiometric assay techniques were used for determination of serum concentrations of the reported hormones, including prolactin, GH, FSH, LH, TSH, insulin, cortisol, and thyroid hormones; serum IGF-I levels were measured after acid-ethanol extraction $(8-10)$.

Dynamic endocrine studies were performed in the index cases, a pair of monozygotic twin sisters, between 2 and $18 \mathrm{y}$ of age $(1,7)$. Concomitant 6 -h secretory profiles for $\mathrm{GH}$, prolactin, TSH, LH, and FSH were obtained in a newborn CDG patient with polycythemia, by using deconvolution analysis on sequential hormone concentrations in serum samples obtained during an isovolumetric, partial exchange transfusion (8). All other data were derived from spare serum, that had been obtained for different diagnostic purposes.
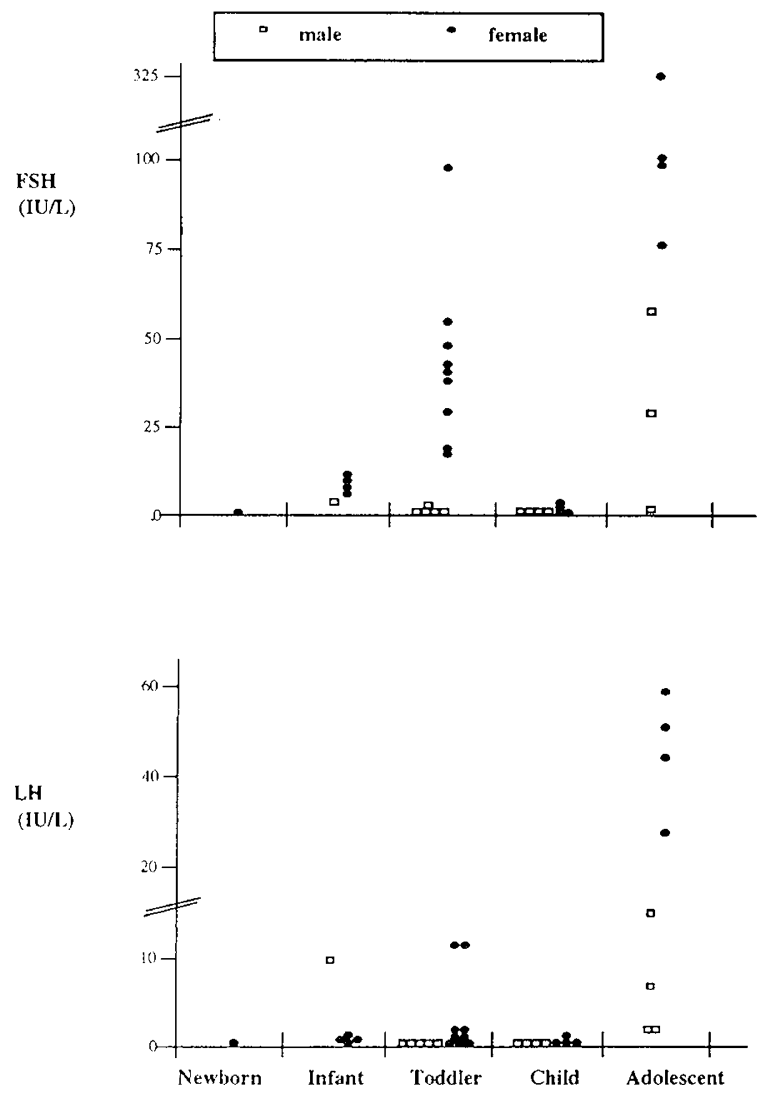

Deconvolution analysis of hormone secretory profiles was performed according to and by courtesy of Dr. J. D. Veldhuis (University of Virginia, Charlottesville, VA) (11).

FSH bioactivity studies were performed in 1990 by courtesy of Drs. A. J. W. Hsueh and K. Nishimori (University of California San Diego, La Jolla, CA), using the in vitro granulosa cell aromatase bioassay, as previously described $(12,13)$.

\section{RESULTS}

Gonadal axis. Basal serum concentrations of FSH and LH were age dependent (Fig. 1, left panels). FSH levels were particularly elevated in female toddlers (normal, $<5 \mathrm{IU} / \mathrm{L}$ ) and in female and some male adolescents (normal, $<20 \mathrm{IU} / \mathrm{L}$ ). $\mathrm{LH}$ levels were consistently increased in female teenagers (normal, $<20 \mathrm{IU} / \mathrm{L})$.

GnRH ( $1 \mu \mathrm{g} / \mathrm{kg}$ i.v. $)$, administered at the ages of 2 and $13 \mathrm{y}$ to the monozygotic sisters, elicited at both ages a homogeneous hyperresponse of FSH and $\mathrm{LH}$, the resulting serum levels at 13 $\mathrm{y}$ being higher than at $2 \mathrm{y}$ (Fig. 1, upper right panels). Deconvolution analysis of the serum profiles during these tests revealed that the serum half-lives of $\mathrm{LH}$ were extremely long (455-755 min; normal, $\sim 60 \mathrm{~min}$ ) and that the FSH bursts were delayed and very prolonged, the FSH half-lives being 42-256 min (normal, $\sim 240 \mathrm{~min}$ ).
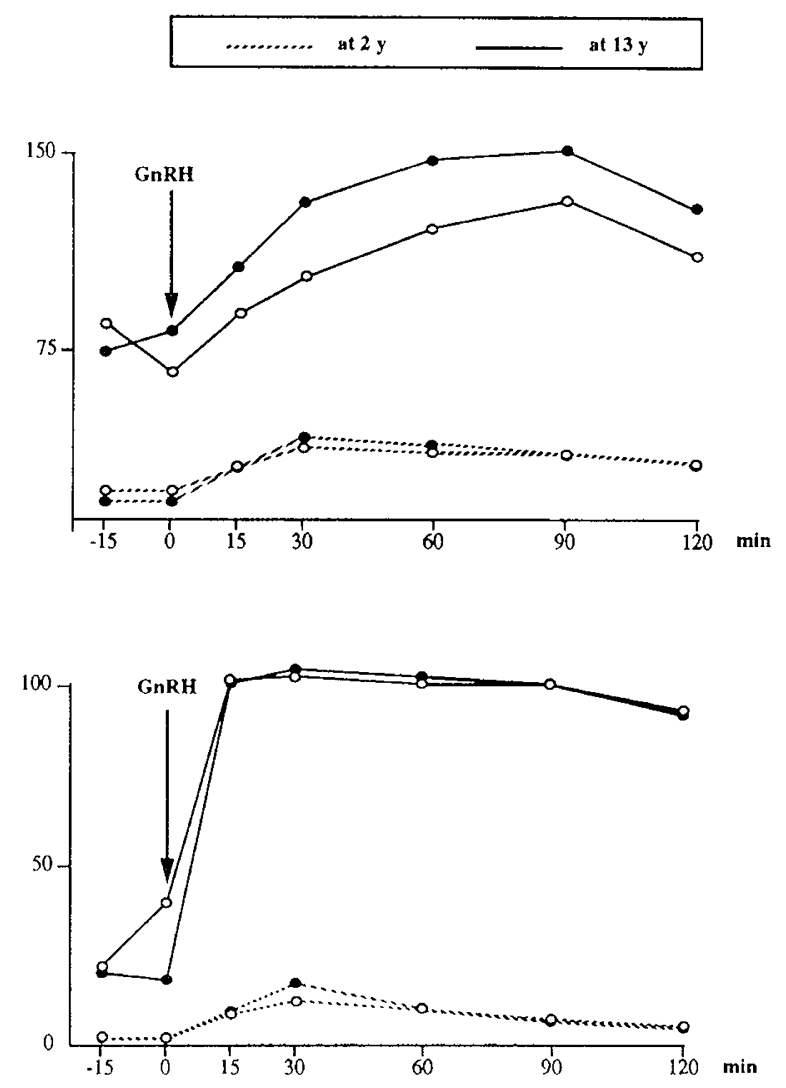

Figure 1. Left panels, serum FSH and LH concentrations, measured singly or sequentially, at different ages in 26 patients with the CDG syndrome type 1 . Right panels, FSH and LH responses to GnRH at the ages of 2 and 13 y in monozygotic twin sisters $(\bigcirc$ and $)$ with the CDG syndrome type 1. Note the homogeneous, cxaggerated, and prolonged FSH and LH responses at $2 \mathrm{y}$ and particularly at $13 \mathrm{y}$. 
Male patients have normally differentiated external genitalia, suggestive of prenatal chorionic gonadotropin bioactivity. Affected boys virilize at puberty, although testicular volume remains small ( $\leq 5 \mathrm{~mL}$; normal adult, $20-25 \mathrm{~mL}$ ). Basal serum testosterone concentrations were normally elevated in a 2 -moold male infant $(11.9 \mathrm{nmol} / \mathrm{L})$ and in four male teenagers (6.7-31.3 nmol/L), indicating endogenous $\mathrm{LH}$ bioactivity.

In contrast, serum estradiol levels in four adolescent girls were found to remain in the prepubertal range $(<50 \mathrm{pmol} / \mathrm{L})$; ultrasound examination revealed the bilateral presence of ovaria without signs of follicular activity; breast development failed to occur. Basal serum testosterone levels were measured in two of the female teenagers and were elevated ( 3.5 and 3.8 $\mathrm{nmol} / \mathrm{L}$; normal $<3.5 \mathrm{nmol} / \mathrm{L}$ ), whereas the serum androstenedione levels were normal $(2.7$ and $3.1 \mathrm{nmol} / \mathrm{L}$; normal $2.5-5.0 \mathrm{nmol} / \mathrm{L}$ ) and the serum dehydroepiandrosterone sulfate concentrations were not suggestive of adrenal zona reticularis hyperfunction ( 4.6 and $5.6 \mu \mathrm{mol} / \mathrm{L}$; normal $1.3-6.5 \mu \mathrm{mol} / \mathrm{L}$ ). Together, the in vivo data obtained in female adolescents with the $\mathrm{CDG}$ syndrome are consistent with the concept of an exaggerated LH-driven theca cell function and a lack of FSHdependent granulosa cell function, in spite of the striking availability of immunoreactive FSH.

The administration of low doses of human menopausal gonadotropins (75 IU FSH intramuscularly once daily for $7 \mathrm{~d}$; Humegon, Organon, The Netherlands) to the monozygotic twin sisters at the age of 13 y resulted in a definite ovarian response in one of the girls, as judged by a concomitant rise of serum estradiol to $437 \mathrm{pmol} / \mathrm{L}$, by development of a single ovarian follicle (Fig. 2) and by rapid breast budding. The twin girl responded also, but in a less convincing fashion.

In vitro, using the rat granulosa cell aromatase bioassay, the serum of the aforementioned twins was found to have a low normal FSH bioactivity ( 71 and $120 \mathrm{IU} / \mathrm{L} ; 80-246 \mathrm{IU} / \mathrm{L}$ in age-matched girls with gonadal dysgenesis or bilateral ovariectomy) and a low normal bioactive/immunoreactive ratio ( 0.15 and $0.21 ; 0.19-0.69$ in the controls). Chromatofocusing

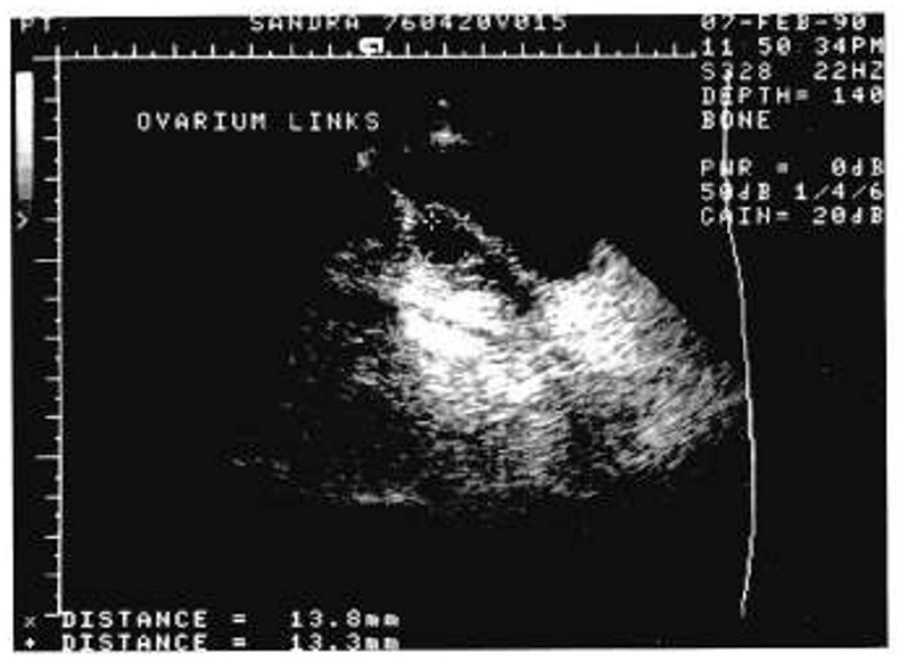

Figure 2. Ultrasonographic visualization of ovarian follicular development (diameter $>13 \mathrm{~mm}$ ) in response to exogenous gonadotropin administration in a girl with hypergonadotropic hypogonadism as part of the CDG syndrome type 1 at the age of $13 \mathrm{y}$. analysis revealed no substantial changes in the charge pattern of the bioactive FSH fraction, which eluted at a normal $\mathrm{pH}$ (3.8-5.2; 4.0-4.9 for FSH of postmenopausal women).

Thyroid axis. Basal serum TSH levels appear to be age dependent (Fig. 3, left panel), being elevated in infancy ( $>6$ $\mathrm{mU} / \mathrm{L}$; normal $0.15-4.6 \mathrm{mU} / \mathrm{L}$ ) and normal during late childhood and adolescence, the toddlers forming a transition group. Administration of TRH ( $200 \mu \mathrm{g}$ i.v.) to the monozygotic twins at the ages of $2,3,13$, and $17 \mathrm{y}$ also evoked gradually decreasing TSH responses (Fig. 3, right panel).

Serum TBG concentrations were consistently low for age ( $n$ $=15$; median, $9.8 \mathrm{mg} / \mathrm{L}$; range, $5.3-16.5 \mathrm{mg} / \mathrm{L}$; normal, $14-24$ $\mathrm{mg} / \mathrm{L})$, including a measurement at the age of $1 \mathrm{~d}(13.4 \mathrm{mg} / \mathrm{L})$. Free thyroxine concentrations were low to normal at all ages ( $n$ $=10$; median, $9.0 \mathrm{pmol} / \mathrm{L}$; range, $4.3-14.3 \mathrm{pmol} / \mathrm{L}$; normal, 9.0-24.5 pmol/L).

Prolactin. Basal serum prolactin concentrations were normally elevated $(>100 \mu \mathrm{g} / \mathrm{L})$ in all three studied newborns and normally low $(<15 \mu \mathrm{g} / \mathrm{L})$ in 22 of the 26 patients examined after the neonatal period. Elevated basal prolactin levels were observed in four female patients, two girls aged 2 y (31 and 39 $\mu \mathrm{g} / \mathrm{L}$ ) and the monozygotic sisters. In the latter two cases, the basal hyperprolactinemia decreased gradually over a course of $15 \mathrm{y}$ and was sensitive to the release-inhibitory action of exogenous L-dopa ( $150 \mathrm{mg}$ orally) at the age of $3 \mathrm{y}$; the response of prolactin to stimulation with TRH (200 $\mu \mathrm{g}$ i.v.) also normalized gradually (normal, $<80 \mu \mathrm{g} / \mathrm{L}$ ) (Fig. 4).

Growth hormone and insulin. Basal serum GH concentrations were normally low in the 14 examined boys, being $<10$ $\mu \mathrm{g} / \mathrm{L}$ in 13 of them, and $13.5 \mu \mathrm{g} / \mathrm{L}$ in the youngest patient, aged 2 mo. In contrast, basal GH levels were $<10 \mu \mathrm{g} / \mathrm{L}$ in only four of the 12 girls studied, being augmented $(10-58 \mu \mathrm{g} / \mathrm{L})$ in five of them, and strikingly elevated on three occasions: 192 and $120 \mu \mathrm{g} / \mathrm{L}$ in different infants aged 1 and $2 \mathrm{mo}$, and 144 $\mu \mathrm{g} / \mathrm{L}$ in one of the twin sisters at the age of $2 \mathrm{y}$. In the latter three patients, basal GH concentrations $<20 \mu \mathrm{g} / \mathrm{L}$ were documented within the 6 mo following.

In the monozygotic pair, the glycemic, $\mathrm{GH}$, and insulin responses to glucagon administration $(0.1 \mathrm{mg} / \mathrm{kg}$ intramuscularly) were examined at the ages of 2,13, and 17 y (Fig. 5
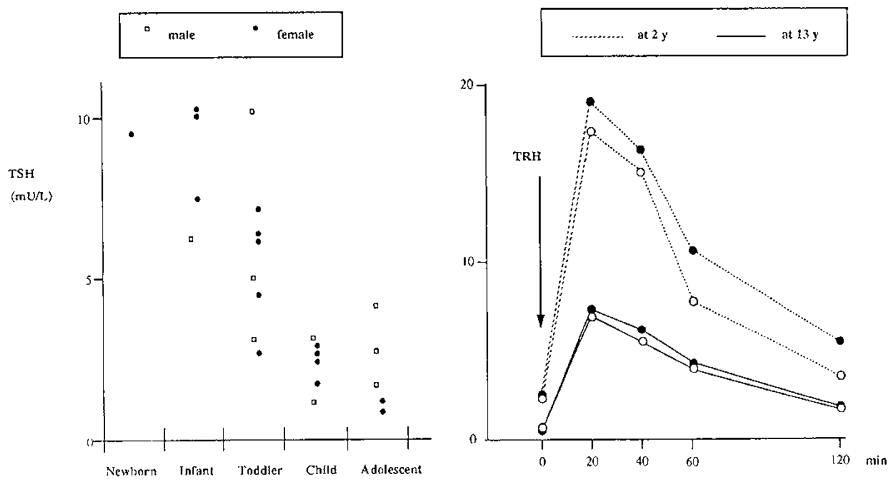

Figure 3. Left panel, basal scrum TSH concentration, measured singly or scquentially at different ages in 26 patients with the CDG syndrome type 1. Normal TSH concentration, 0.15-4.6 mU/L. Right panel, TSH response to $\mathrm{TRH}$ at the ages of 2 and $13 \mathrm{y}$ in monozygotic twin sisters ( $\mathrm{O}$ and $)$ with the CDG syndrome type 1 . 


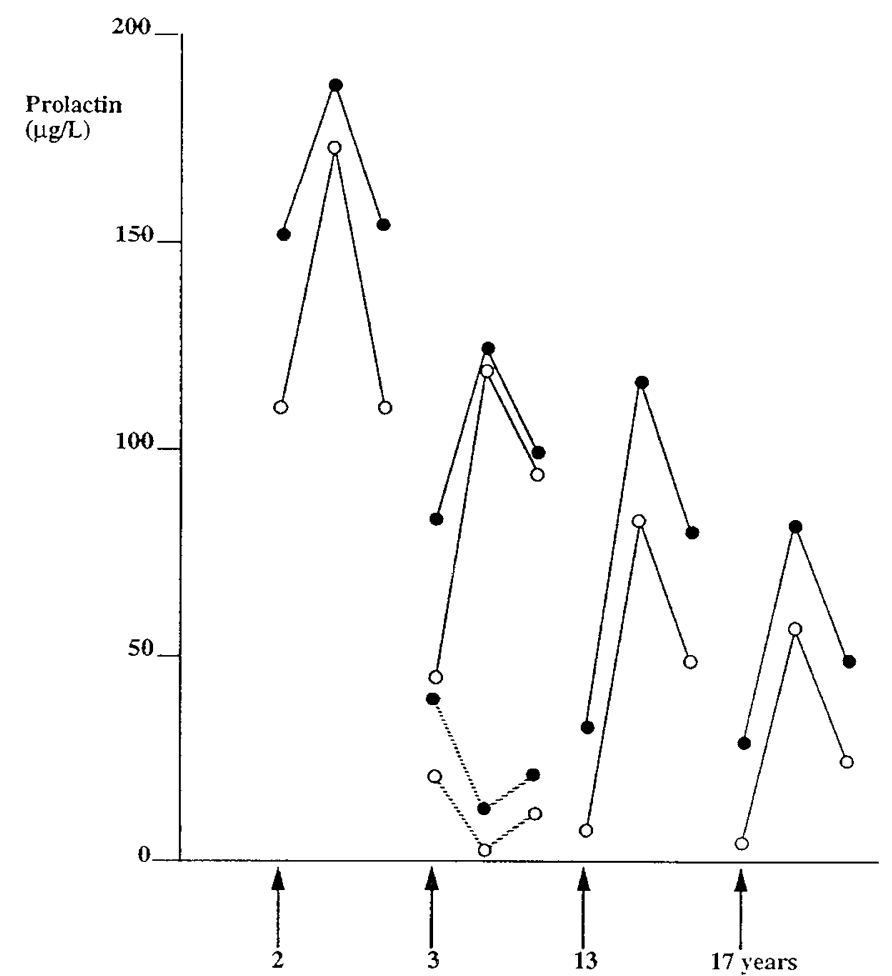

Figure 4. Hyperprolactinemia in monozygotic twin sisters $(\mathrm{O}$ and $)$ with the CDG syndrome type 1. Basal scrum prolactin concentrations at the ages of 2 , 3,13 , and $17 \mathrm{y}$ are plotted above the arrows. Prolactin responses 20 and $60 \mathrm{~min}$ after TRH administration are interconnected by unbroken lines. Note the gradual decline of both basal and peak prolactin concentrations, and the consistency in the responses of both sisters. Still at the age of $3 \mathrm{y}$, prolactin levels 2 and $3 \mathrm{~h}$ after L-dopa administration are interconnected by dotted lines.

depicts the results at age $13 \mathrm{y}$ ). The consecutive tests consistently resulted in a normal glycemic response and a biphasic GH rise with a paradoxally clevated component during the initial phase of hyperglycemia (normal, $<10 \mu \mathrm{g} / \mathrm{L}$ ) and an adequate response after the decline of glycemia (normal, $10-40 \mu \mathrm{g} / \mathrm{L}$ ). At age $13 \mathrm{y}$, the insulin response was strikingly augmented (peak concentrations of 4234 and $2534 \mathrm{pmol} / \mathrm{L}$; normal, $<1440 \mathrm{pmol} / \mathrm{L}$ ); this insulin hypcrresponse was not observed at the age of 2 y (peak levels of 144 and $230 \mathrm{pmol} / \mathrm{L}$ ), but was similar at the age of $17 \mathrm{y}$.

Other endocrine studies. Serum IGF-1 concentrations were low or low normal in infants and children $(n=15$ below age of $9 \mathrm{y}$; median, $33 \mu \mathrm{g} / \mathrm{L}$; range, $12-92 \mu \mathrm{g} / \mathrm{L}$; normal, 77-135 $\mu \mathrm{g} / \mathrm{L})$ and low to normal in adolescents $(n=8$; median, 267 $\mu \mathrm{g} / \mathrm{L}$; rangc, 107-437 $\mu \mathrm{g} / \mathrm{L}$; normal, 350-504 $\mu \mathrm{g} / \mathrm{L}$ ), and appeared to be gender independent.

Adrenarche appears to occur normally, as serum dehydroepiandrosterone-sulfate levels were low $(<0.2 \mu \mathrm{mol} / \mathrm{L} ; n=7)$ under the age of $6 \mathrm{y}$, becamc detectable thereafter, and were normal during adolescence $(n=5$; median, $4.6 \mu \mathrm{mol} / \mathrm{L}$; range, 1.3-5.6 $\mu \mathrm{mol} / \mathrm{L}$; normal, $1.1-6.8 \mu \mathrm{mol} / \mathrm{L})$.

Scrum transcortin levels were distinctly low $(n=5$; range $8-25 \mathrm{mg} / \mathrm{L}$; normal range, $32-50 \mathrm{mg} / \mathrm{L}$ ) and did not alter between the age of 2 and $17 \mathrm{y}$ in the twins; free cortisol concentrations and circulating sex-hormone binding globulin levels were found to be normal.
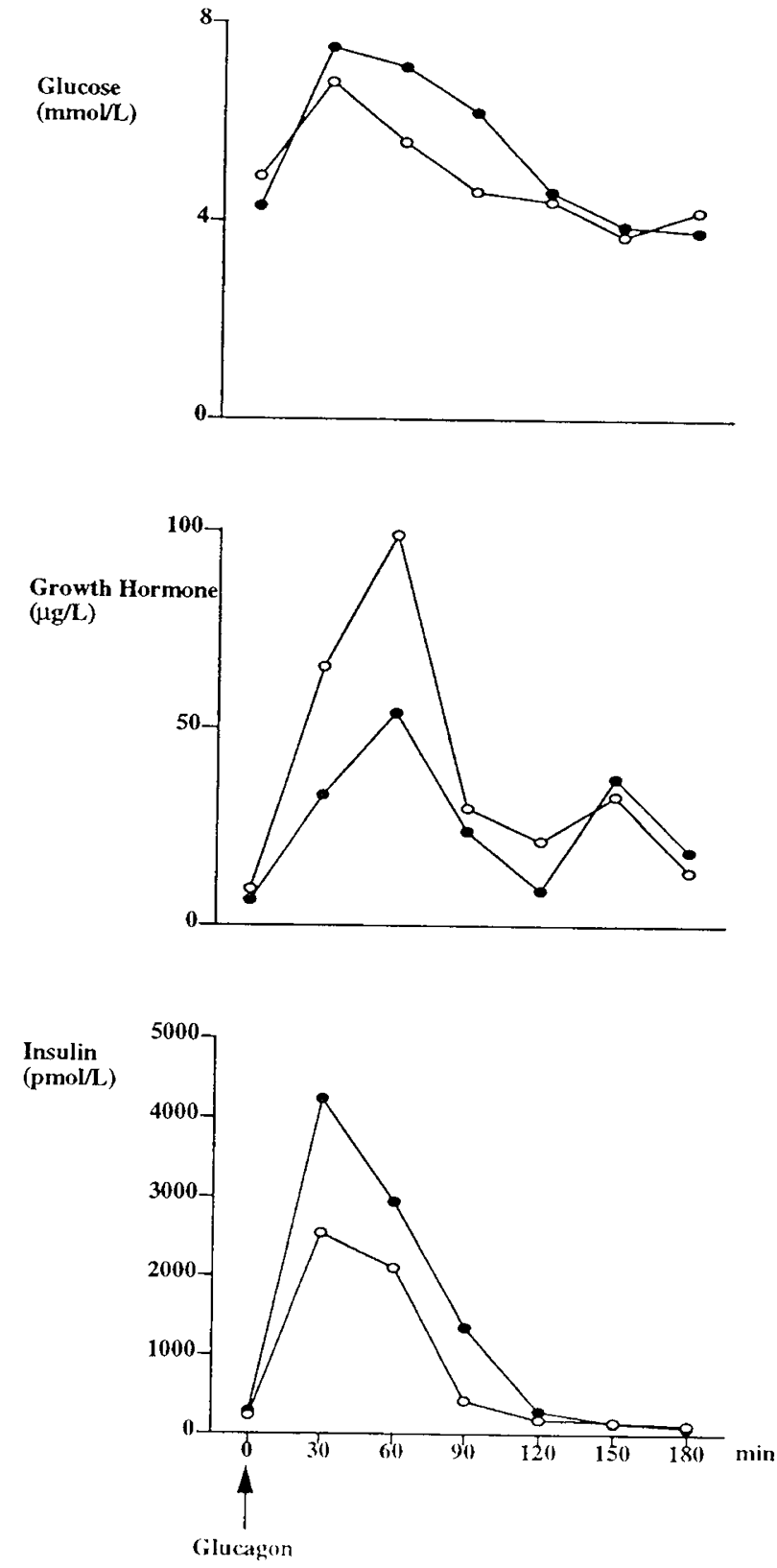

Figure 5. Blood glucose, serum $\mathrm{GH}$, and insulin levels in monozygotic twin sisters ( $\bigcirc$ and $)$ ) with the CDG syndrome type 1 during a glucagon test ( $3 \mathrm{mg}$ intramucularly) at the age of $13 \mathrm{y}$. The glycemic response is normal. GH presents a paradoxical and impressive secretory response during the initial hyperglycemia, followed by a second phase of hypersecretion, thus yielding a pronounced biphasic pattern. The insulin response presents a strikingly clevated amplitude.

In a single 5-d-old polycythemic girl with CDG syndrome type 1, 6-h secretory profiles of FSH, $\mathrm{LH}, \mathrm{GH}$, prolactin, and TSH were derived during a partial exchange transfusion (Fig. 6). FSH and LH concentrations were undetectably low $(<1$ $\mathrm{U} / \mathrm{L}$ ) throughout the 6-h period, as in polycythemic but otherwise healthy female newborns (8). GH displayed a neonatal pattern of exclusively pulsatile hypersecretion with an interburst interval of 60 min and a calculated GH half-life of 27 min, comparable to polycythemic controls (9). The serum concentrations of prolactin were at the normal neonatal level, but the mode of prolactin release was particular, as approxi- 
Serum Concentration

$\mathrm{GH}$

$(\mathrm{ug} / \mathrm{L})$
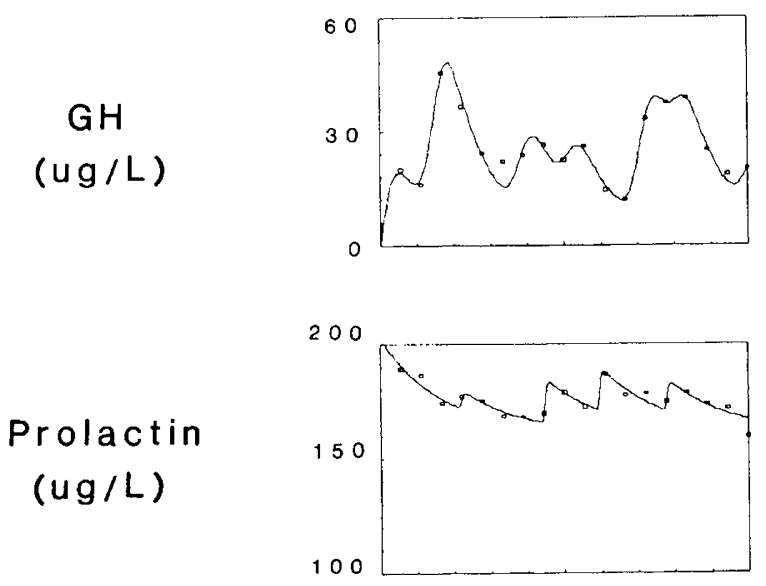

(ug/L/min)

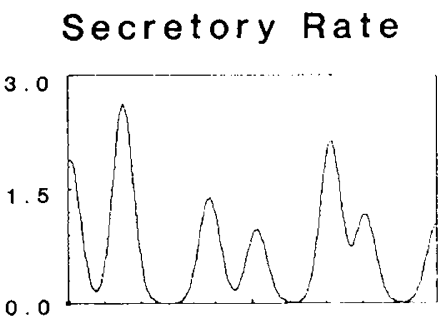

$(\mathrm{ug} / \mathrm{L} / \mathrm{min})$

0.0
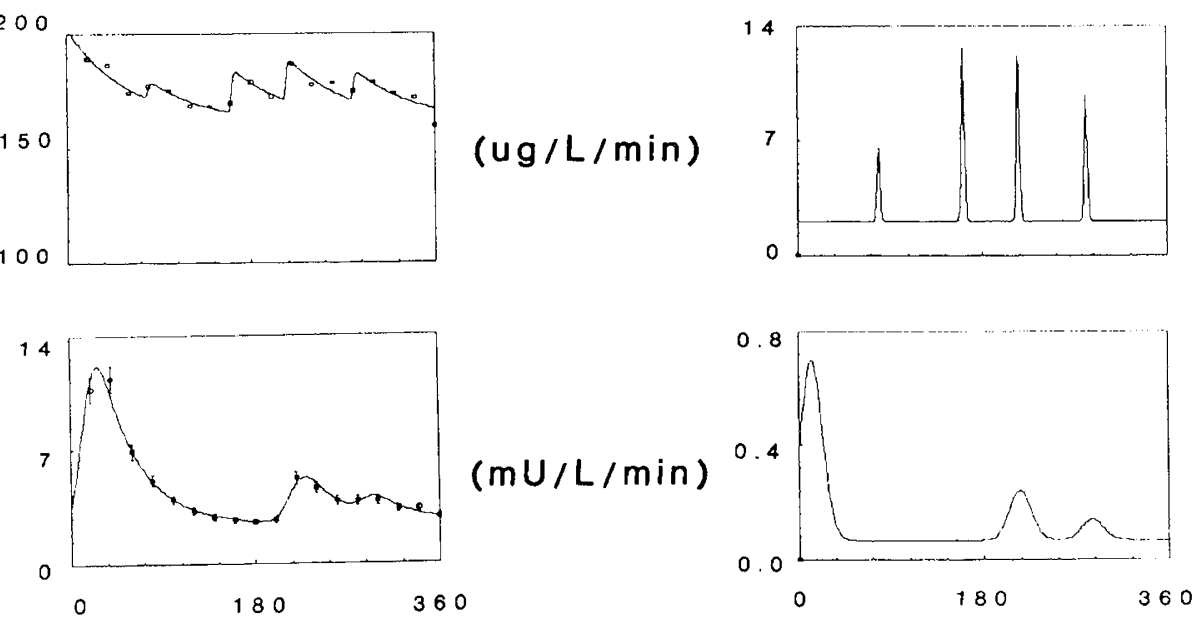

Time (min)

Figure 6. GH, prolactin, and TSH serum concentration and secretory rate profiles obtained over $6 \mathrm{~h}$ from a polycythemic newborn with the CDG syndrome type 1 .

mately $15 \%$ of the circulating prolactin was secreted in a pulsatile fashion, whereas prolactin is released by polycythemic controls in an exclusively tonic way $(9,14)$. Serum TSH concentrations were in the high normal neonatal range, and TSH was secreted through a combination of tonic and pulsatile release, as in polycythemic control newborns (10). The mean pulse amplitude, duration, and frequency of TSH secretion were not exceptional, the interburst interval being $136 \mathrm{~min}$, but the TSH half-life was short, namely 25 min (control 56-85 min) (10).

The hypothalamic-pituitary morphology as visualized by magnetic resonance imaging $(n=7)$ was normal (Fig. 7). The patients from whom growth data were available $(n=9)$ presented a height and weight progression at the level of the third percentile for chronologic age [see Jaeken et al. (1) for illustrative growth charts].

\section{DISCUSSION}

This report provides a first view on the spectrum of endocrine abnormalities encountered from birth through adolescence in patients with a major disorder of glycoprotein glycosylation, namely the CDG syndrome type 1 . This spectrum was found to include gender- and age-dependent hypergonadotropic hypogonadism; euthyroidism with transient hyperthyrotropinemia; inconsistent, but impressive hyperprolactinemia and hypersomatotropism; age-dependent insulin hyperresponsiveness to glucagon; low serum levels of hormone-carrier proteins as TBG and transcortin; and prolonged or shortened circulating hormone half-lives, as for $\mathrm{LH}$ and $\mathrm{TSH}$, respec-

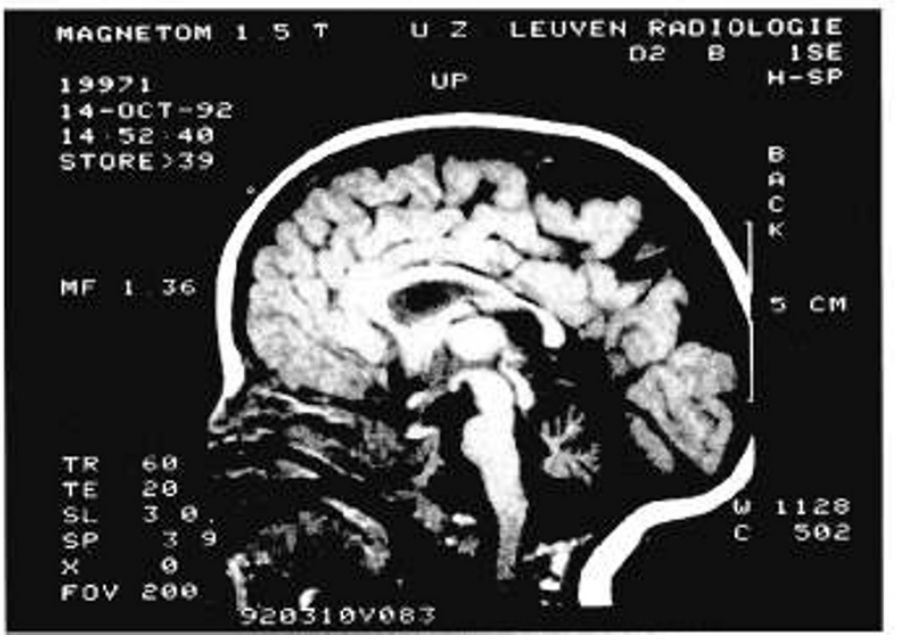

Figure 7. Magnetic resonance imaging of the intracranial midline structures of a girl with the CDG syndrome type 1 at the age of 7 mo. The hypothalamopituitary stalk, the anterior pituitary gland, and the characteristic hyperdense signal of the posterior pituitary gland in the sella turcica appear normal. Note the marked cerebellar hypoplasia, a hallmark of the CDG syndrome type 1 .

tively. Thus, this complex, heterogeneous and age-dependent entity is the first human endocrinopathy recognized to be based, either directly or indirectly, on glycosylation-related dysfunctions, plausibly including modifications of secretory pathways; modulations of circulating half-lives; perturbations of glycoprotein stability; disequilibria in carrier protein availability and binding; alterations in receptor configuration, binding, and activation; deregulations in autocrine and paracrine actions, and resetting of endocrine control and feedback loops. 
The hypothalamo-pituitary-gonadal axis was consistently found to be pcrturbed in the studied patients, offering a picture of hypergonadotropic hypogonadism. Interestingly, the in vivo bioactivity of LH, which normally has fewer glycosylation sites and carries more sulfated carbohydrates compared with FSH [reviewed in Ronin (15)], appeared to be less affected than the bioactivity of FSH. In the adolescent twin girls, the reduced in vivo bioactivity of FSH was studied in more detail. The administration of exogenous gonadotropins, primarily extracted FSH, promptly elicited estrogen secretion and follicular development, suggestive of target organ responsiveness. Recently, this phenomenon was also observed in a Japanese girl with CDG syndrome type 1 (16). Moreover, the in vitro bioactivity of FSH from the CDG patients was not severely reduced, when examined in a rat granulosa cell bioassay. Together, these findings suggest that the strikingly reduced bioactivity of FSH in CDG patients is of multifactorial origin, possibly a combination of minor alterations in the configuration of both hormone and receptor, and in their microenvironment, including LH, inhibins, activins, follistatin, IGF, steroids, and their respective receptors and binding proteins.

Although patients appeared to be euthyroid throughout the studied age range, basal TSH concentrations and TRH-induced TSH levels were found to be elevated in the youngest children compared with older individuals. At present, the pathophysiologic basis for this observation is uncertain, particularly as the evaluation of the thyroid status in CDG patients is complicated by the coexisting TBG deficiency and potential alterations in the binding of thyroid hormones to this carrier protein. However, it is possible that TSH action is more sensitive to appropriate glycosylation of itself and/or its receptor during infancy compared with later in life $(17,18)$. Furthermore, it is noteworthy that TBG deficiency was already documented in a 1-d-old affected newborn, indicating that TBG may be an carlier serum marker for the disorder than abnormal transferrin isoforms (19).

Hyperprolactinemia was documented in a minority of the female patients. The mechanism underlying this phenomenon and the prolactin hyperresponsiveness to TSH-releasing hormone is hitherto unclear. A decreased inhibitory action of dopamine may be involved, possibly through decreased hypothalamic dopamine release rather than through diminished pituitary sensitivity to dopamine, as the hyperprolactinemia was suppressible by exogenous L-dopa. However, other mechanisms may interfere; for example, the hypothalamic secretion of TRH could be augmented, or the function of the activin-A receptor could be defective, resulting in a decreased paracrine inhibition of prolactin release $(20,21)$.

Excessively elevated serum GH concentrations were detected in some infants, and biphasic GH hyperresponses were repeatcdly observed upon glucagon stimulation in the index cases. Again, the pathogenesis of these exceptional findings is likely to be complex. Low feedback action by circulating IGF-1 may be involved, particularly at younger ages. Moreover, the secretion of ncuropeptides modulating GH release, such as GH-releasing factor, galanin, somatostatin, dopamine, and activin (21) could be altered, or the presumably different glycosylation state of their respective receptors may result in a net augmentation of the secretory activity of the somatotroph. The basis for the apparent sexual dimorphism in GH levels is equally uncertain, one possibility being that it is linked to the aforementioned dimorphism of gonadotropin secretion and action.

In the index cases, the glycemic response to glucagon was normal at all examined ages, but the concomitant insulin response was of a striking magnitude during adolescence, whereas the latter was not the case at the age of $2 \mathrm{y}$. These observations are indicative of a gradually developing insulin resistance, possibly related to inappropriate glycosylation of the insulin receptor. It is noteworthy that the association of insulin resistance and hypergonadotropic hypogonadism was apparently first noted in 1956 by Dr. Bassoe in his report on a female and a male adult with "familial congenital muscular dystrophy," born in the late 1920s in Norway (22). Interestingly, the details and illustrations in this publication today permit one to infer credibly that these adults suffered in fact from the CDG syndrome type 1 and, therefore, that this report represents the first clinical and endocrinologic description of the CDG syndrome type 1 in the adult.

The profound alterations in the endocrine homeostasis of children with the CDG syndrome type 1 point to the vital importance of glycoprotein glycosylation in the endocrine physiology of the human between birth and adulthood. In addition, the unique endocrine paradigm observed in the CDG syndrome type 1 may offer novel insights into the pathogenesis of hitherto enigmatic conditions. For example, first, it is now plausible that the hypergonadotropic hypogonadism in female adults with galactosemia (23) - which is a secondary CDG syndrome $(2,24)$-is equally based on a glycosylation defect. Second, female adolescents with the CDG syndrome type 1 were found to present a picture including an augmented ratio of LH/FSH effect, anovulation, hirsutism, hyperprolactinemia, and insulin resistance, a constellation reminiscent of the polycystic ovary syndrome (25). The intriguing parallelism between endocrine characteristics of a glycosylation disorder and of polycystic ovary syndrome deserves further investigation.

Acknowledgments. The authors thank all collaborators in this study, particularly Drs. A. J. W. Hsuch and K. Nishimori (Stanford, CA) for FSH bioactivity studies; Dr. J. D. Veldhuis and P. Azimi (Charlottesville, VA) for deconvolution analyses and preparation of Figure 6; Dr. M. Lodewcyckx for participation in early studies; Drs. R. Bouillon, W. Heyns, M. De Roo, and P. Koninckx for laboratory support; D. Lemmens for editorial assistance; Drs. E. Eggermont, H. Devlieger, P. Casaer; B. Schluter, G. Burke, W. Andler, and F. Aksu (Datteln, Germany), Dr. N. Buist (Portland, OR), Dr. D. Isherwood (Liverpool, UK), Drs. L. Pavone, A. Fiumara, and R. Barone (Catania, Sicily, Italy), Dr. M. Di Rocco (Genova, Italy), Dr. D. Valle (Baltimore, MD), Dr. R. Matalon (Miami, FL), Dr. V. Ramaekers (Aachen, Germany), Dr. A. David (Nantes, France), Dr. D. Chaigne (Strasbourg, France), Dr. S. Stokler (Graz, Austria), Dr. A. Slonim (Manhasset, NY), Dr. S. Kahler (Durham, NC), and Dr. U. Stephani (Kiel, Germany) for sharing clinical experience and for active study participation. 


\section{REFERENCES}

1. Jacken J, Stibler H, Hagberg B 1991 The carbohydrate-deficient glycoprotein syndrome. Acta Paediatr Scand Suppl 375

2. Jacken J, Carchon H, Stibler H 1993 The carbohydrate-deficient glycoprotein syndromes: pre-Golgi and Golgi disorders? Glycobiology 3:423-428

3. Van E Geet C, Jaeken $\mathrm{J} 1993$ A unique pattern of coagulation abnormalitics in carbohydrate-deficient glycoprotein syndrome. Pediatr Res 33:540-541

4. Yamashita K, Idco H, Ohkura T, Fukushima K, Yuasa I, Ohno K, Takeshita K 1993 Sugar chains of serum transferrin from patients with carbohydrate deficient glycoprotein syndrome. J Biol Chem 268:5783-5789

5. Petersen MB, Brostrom K, Stibler H, Skovby F 1993 Early manifestations of the carbohydrate-deficient glycoprotein syndrome. J Pediatr 122:66-70

6. Jacken J, Schachter H, Carchon H, De Cock P, Coddeville B, Spik G 1994 Carbohydrate deficient glycoprotein syndrome type II: a deficiency in Golgi localised $N$-acetyl-glucosaminyltransferase II. Arch Dis Child 71:123-127

7. Jacken J, Vanderschueren-Lodeweyckx M, Casaer P, Snoeck L, Corbeel L, Eggermont E, Ecckels R 1980) Familial psychomotor retardation with markedly fluctuating serum prolactin, FSH and GH levels, partial TBG deficiency, increased serum arylsulphatase A, and increased CSF protein: a new syndrome? Pediatr Res 14:170

8. de Zegher F, Devlieger H, Veldhuis JD 1992 Pulsatile and sexually dimorphic secretion of luteinizing hormone in the human infant on the day of birth. Pediatr Res 32:605-607

9. de Zegher F, Devlieger H, Veldhuis JD 1993 Properties of growth hormone and prolactin hypersecretion by the human newborn on the day of birth. J Clin Endocrinol Metab 76:1177-1181

10. de Zegher F, Vanhole C, Van den Berghe G, Devlieger H, Eggermont E, Veldhuis JD 1994 Propertics of thyroid stimulating hormone and cortisol secretion by the human newbom on the day of birth. J Clin Endocrinol Metab 79:576-581

11. Veldhuis JD, Johnson ML 1992 Deconvolution analysis of pulsatile hormone data. Methods Enzymol 210:539-575

12. Dahl KD, Bicsak TA, Hsueh AJW 1988 Naturally occurring antihormones: secretion of FSH antagonists by women treated with a GnRH analog. Science 239:72-74

13. Dahl KD, Jia XC, Hsuch AJW 1989 Granulosa ccll aromatase bioassay for folliclestimulating hormone. Methods Enzymol 168:414-422
14. de Zegher F, Van den Berghe G, Devlieger H, Eggermont E, Velahhuis JD 1993 Dopamine inhibits neonatal growth hormone and prolactin hypersecretion. Pediatr Res 34:642-645

15. Ronin C 1992 Glycosylation of pituitary hormones: a necessary and multistep control of biopotency. Glycoconj J 9:279-283

16. Ohzeki $\mathrm{T}$, Motozumi H, Hanaki K, Ohtahara H, Urashima H, Tsukuda T, Kobayashi S, Shiraki K, Ohno K 1993 Carbohydrate-deficient glycoprotein syndrome in a girl with hypogonadism due to inactive follicle stimulating hormone. Horm Metab Res 25:646-648

17. Gyves PW, Gesundheit N, Stannard BS, DeCherney GS, Weintraub BD 1989 Alterations in the glycosylation of secreted thyrotropin during ontogenesis. J Biol Chem 264:6104-6110

18. Papandrcou M-J, Persani L, Asteria C, Ronin C, Beck-Peccoz P 1993 Variable carbohydrate structures of circulating thyrotropin as studied by lectin affinity chromatography in different clinical conditions. J Clin Endocrinol Metab 77:393-398

19. Clayton P, Winchester B, Di Tomaso E, Young E, Keir G, Rodeck C 1993 Carbohydrate-deficient glycoprotein syndrome: normal glycosylation in the fetus. Lancet 341:956

20. Kitaoka M, Kojima I, Ogata E 1988 Activin-a: a modulator of multiple types of anterior pituitary cells. Biochem Biophys Res Commun 157:48-54

21. Struthers RS, Gaddy-Kurten D, Vale WW 1992 Activin inhibits binding of transcription factor pit-1 to the growth hormone promoter. Proc Natl Acad Sci USA 89:1145111455

22. Bassoe HH 1956 Familial congenital muscular dystrophy with gonadal dysgenesis. J Clin Endocrinol Metab 16:1614-1621

23. Kaufman FR, Kogut MD, Donnell GN, Goebelsmann U, March C, Koch R 1981 Hypergonadotropic hypogonadism in female patients with galactosemia. $N$ Engl $J$ Med 304:994-998

24. Jaeken J, Kint J, Spaapen L 1992 Serum lysosomal enzyme abnormalities in galactosemia. Lancel 340:1472-1473

25. McKenna TJ 1988 Pathogenesis and treatment of polycystic ovary syndrome. N Engl J Med 318:558-562 